Revista Oficial del Poder Judicial

ÓRGANO DE INVESTIGACIÓN DE LA CORTE SUPREMA DE JUSTICIA DE LA REPÚBLICA DEL PERÚ

Vol. 9, n.' 11, enero-junio, 2019, 325-354

ISSN versión impresa: 1997-6682

ISSN versión electrónica: 2663-9130

DOI: https://doi.org/10.35292/ropj.u9i11.11

\title{
El derecho humano a un debido proceso frente al procedimiento administrativo peruano
}

The fundamental right to a due process versus the Peruvian Administrative proceeding

\author{
(0) \\ JAVIER EDUARDO JIMÉNEZ VIVAS \\ Corte Superior de Justicia de Lima Este \\ (Lima, Perú) \\ Contacto:jjimenezui@pj.gob.pe \\ https://orcid.org/0000-0001-7972-2804
}

\begin{abstract}
RESUMEN
Este ensayo presenta al debido proceso, en su condición de derecho humano constitucionalizado, frente al procedimiento administrativo peruano; describe el camino recorrido por el primero hasta su final reconocimiento en el derecho administrativo, a través de diversos instrumentos normativos, jurisprudenciales y doctrinarios; muestra la actual consolidación de dicho derecho en sede administrativa y ofrece claves para su interpretación futura y atención desde las ópticas nacional y comparada.
\end{abstract}


Palabras clave: derecho humano, debido proceso, derecho administrativo, debido procedimiento administrativo, procedimiento administrativo.

\section{ABSTRACT}

This assay presents the due process of law as a constitutionalized human right facing the Peruvian administrative proceeding. It describes the road traveled by the former up to its ultimate acknowledgement, in the administrative law, through the different regulatory, doctrinarian and jurisprudential instruments. It shows the present consolidation of said right in an administrative headquarters and offers clues for its future interpretation and attention, from the national and compared viewpoint.

Key words: fundamental right, due process, administrative law, due administrative process, administrative proceeding.

\section{Recibido: 31/05/18 Aceptado: 15/08/18}

\section{IDEAS PRELIMINARES}

El derecho es una disciplina humana, por ende, social, y también valorativa (sustentada en valores). Uno de los pilares valorativos de esta disciplina esla noción de «derechos humanos». Esta construcción - uno de los máximos aportes del iusnaturalismo- sirve como premisa de los derechos subjetivos, alberga a un conjunto de valores fundamentales de la sociedad y obliga a los poderes públicos y a los demás particulares. Son «el conjunto de atributos y facultades propios de la persona humana y que son establecidos como tales a nivel global por los distintos ordenamientos jurídicos nacionales, permitiendo su defensa y protección» (Bastos et al. 2012: 204).

Filosóficamente, los derechos humanos son una especie de principios éticos que se proponen ser emblemáticos para el conjunto 
de la comunidad mundial de personas y que, a la vez, buscan ser vinculantes a través de un sistema u ordenamiento jurídico transnacional, convirtiéndose en una especie de moral mínima de nuestra época (Bastos et al. 2012: 204). Diversos instrumentos internacionales han positivizado a los derechos humanos, dotándolos de palpable reconocimiento para facilitar su desarrollo doctrinal, normativo y jurisprudencial. Ello permite que los ordenamientos nacionales constitucionalicen tales derechos, y que de los Tribunales o Cortes constitucionales emanen criterios interpretativos. Uno de estos derechos es el debido proceso.

Entre los instrumentos referidos, destacan la Declaración de Derechos del Hombre y del Ciudadano de 1789, la Declaración Universal de Derechos Humanos suscrita en París el 10 de diciembre de 1948 (Resolución n. 217 de la Asamblea General de las Naciones Unidas), y el Pacto Internacional de Derechos Civiles y Políticos, adoptado mediante Resolución n. ${ }^{\circ} 2200$ A (XXI) del 16 de diciembre de 1996.

Pero hemos indicado que los derechos humanos obligan a los poderes públicos y a los particulares. Se trata de las dos formas de eficacia que la doctrina identifica como «vertical» $y$ «horizontal», respectivamente. La primera significa, a favor de los derechos humanos, que:

a) Su aplicabilidad es inmediata, sin esperar regulación legal.

b) Una reserva de ley orgánica para su regulación.

c) La existencia de un límite infranqueable para dicha regulación.

d) El recurso de inconstitucionalidad si la ley rebasa dicho límite.

e) Una tutela preferente y sumaria para los particulares ante los jueces y tribunales (Gimeno et al. 2007: 191).

Respecto a la eficacia horizontal, esta implica que:

a) Unas veces se trate de garantías frente a todos.

b) Otras veces estemos ante garantías que la Constitución eleva a categoría de derecho. 
c) Muchos casos en los que se produce una colisión de derechos, que ameritan su correspondiente limitación recíproca (Gimeno et al 2007: 105).

Entonces, los derechos humanos despliegan su eficacia sobre los distintos ámbitos del quehacer humano. Veamos cuál fue la eficacia del derecho humano al debido proceso, su evolución, sus problemas y cuáles son sus perspectivas en el ordenamiento jurídico administrativo peruano, así como sus aportes comparativos.

\section{EL DERECHO HUMANO A UN DEBIDO PROCESO}

El origen de la expresión «debido proceso» se encuentra en la carta magna expedida por el rey de Inglaterra Juan sin Tierra el año 1215, cuyo parágrafo 39 se refería al law of the land aplicable a todos los hombres. Posteriormente, dicha carta magna, al ser reexpedida por el rey Eduardo III en el año 1354, incluyó la expresión inglesa due process of law, traducida como debido proceso legal, o simplemente debido proceso (United States Congress 1993: 13). Varios siglos después, y luego de haber sido considerado en las constituciones de algunas de las colonias norteamericanas, el due process of law fue consagrado en la Constitución de los Estados Unidos.

Esto fue posible a través de dos enmiendas, la primera fue la enmienda $V$, según la cual:

Ninguna persona será obligada a responder por delito capital o infamante, sino en virtud de denuncia o acusación por un gran jurado salvo en los casos que ocurran en las fuerzas de mar y tierra, o en la milicia, cuando se hallen en servicio activo en tiempos de guerra o de peligro público; ni podrá nadie ser sometido por el mismo delito dos veces a un juicio que pueda ocasionarle la pérdida de la vida o la integridad corporal; ni será compelido en ningún caso criminal a declarar contra sí mismo, ni será privada de su vida, de su libertad o de su propiedad privada para uso público, sin justa causa (United States Congress 1993: 15). 
La segunda fue la enmienda XIV, que señala:

toda persona nacida o naturalizada en los Estados Unidos y sujeta a su jurisdicción, será ciudadana de los Estados Unidos y del estado en el que resida. Ningún Estado aprobará o hará cumplir ninguna ley que restrinja sus privilegios o inmunidades, sin el debido procedimiento de ley, ni negará a nadie, dentro de su jurisdicción, la igual protección de las leyes.

La cláusula del debido proceso, así planteada, podía ser interpretada como garantía de que el gobierno no dañará a una persona que siga los procedimientos prescritos por la ley, dando por sentado que el solo seguimiento de tales procedimientos generará esa consecuencia. Se trataría de una interpretación amplia de la cláusula, lo cual posibilitaría pensar que lo justo se determina por los procedimientos prescritos, es decir, que el Gobierno puede hacerle a una persona lo que quiera mientras lo haga cumpliendo esos procedimientos (Barber 1986: 151).

En el siglo XX, después de las dos guerras mundiales, existió consenso acerca de la necesidad de otorgar a ciertas instituciones el carácter de garantías internacionales, que permita que cada país las dote de la máxima protección interna. Ello aparece así en la Declaración Universal de Derechos Humanos de 1948 (artículos 8 y 10), en el Pacto Internacional de Derechos Civiles y Políticos de 1966 (numeral 1 de su artículo 14), y en la Convención Americana sobre Derechos Humanos suscrita el 22 de noviembre de 1969 (numeral 1 de su artículo 8).

Reconocido el derecho al debido proceso como derecho humano, después ha sido constitucionalizado en muchos países. Por ejemplo, la Constitución italiana de 1948 lo establece en su artículo $111^{1}$,

1 Traducción libre de «La giurisdizione si attua mediante il giusto processo regolato dalla legge. Ogni proceso si svolge nel contraddittorio tra le parti, in condizioni di 
y la Constitución española de 1978 lo recoge en su artículo 24, numerales 1 y 2 . Ambas cartas magnas ven al debido proceso como un principio constitucional, materializado en el reconocimiento a las personas de varios derechos de índole procesal, concatenados entre sí. La doctrina también sigue esta pauta:

[...] en primer lugar, debe partirse del hecho de que todas las personas ostentan un derecho fundamental procesal previo a los demás, que vamos a llamar la libertad de acceso a un proceso judicial. Y una vez ejercitado este, surgirá entonces el derecho a que el proceso iniciado sea presidido, de forma inexcusable, por un juez imparcial e independiente, cuyos deberes se centran, por una parte, en asegurar tanto el acceso al debido proceso como que este se desarrolle con todas las garantías necesarias y, además, que sea justo $[\ldots]$.

Y, en segundo lugar, este debido proceso, presidido por un juez imparcial e independiente, y desarrollado con todas las garantías -formales y materiales-, termina con la decisión del juez, que es invariable y goza de plena eficacia frente a terceros, además de ser justa (Ureña 2014: 194).

\section{EL DEBIDO PROCESO EN LAS CONSTITUCIONES PERUANAS}

El debido proceso obtuvo rango constitucional en Perú recién con la Constitución Política promulgada el 12 de julio de 1979, pero no de manera expresa. Fue el artículo 233 que, bajo el nombre común de «garantías de la administración de justicia», enumeró la unidad, exclusividad e independencia de la función jurisdiccional, la publicidad de los juicios, la motivación escrita de las resoluciones, la inaplicabilidad por analogía de la ley penal, la instancia plural, entre otras. Pero su Decimosexta Disposición General y Transitoria ratificó «en todas sus cláusulas» el Pacto Internacional de Derechos Civiles y

parità, davanti a un giudice terzo e imparziale. La legge ne assicura la ragionevole durata» (Pisa University Press 2016: 64). 
Políticos, su Protocolo Facultativo y la Convención Americana sobre Derechos Humanos. Con ello adoptó en sede peruana al debido proceso tal como fue incluido en tales instrumentos internacionales.

Diferente fue la Constitución Política promulgada el 29 de diciembre de 1993, su artículo 139, bajo el nombre de «Principios de la función jurisdiccional», incluyó además de un listado similar que el de su antecedente, un numeral 3 con el siguiente texto: «3. La observancia del debido proceso y la tutela jurisdiccional [...]». Los constituyentes, al no necesitar ratificar tratados internacionales, pero estimando dotar a estos del debido reconocimiento e importancia, establecieron en la Cuarta Disposición Final y Transitoria: «Las normas relativas a los derechos y a las libertades que la Constitución reconoce se interpretan de conformidad con la Declaración Universal de Derechos Humanos y con los tratados y acuerdos internacionales sobre las mismas materias ratificados por el Perú».

El desarrollo expuesto hizo que la doctrina identifique una subdivisión en su interior. En primer lugar, el llamado «debido proceso sustancial», que

exige que todos los actos de poder, como normas jurídicas, actos administrativos o resoluciones judiciales inclusive, sean justos, es decir, que sean razonables y respetuosos de los valores superiores, de los derechos fundamentales y de los demás bienes jurídicos constitucionalmente protegidos, a tal punto que su inobservancia sancionase con la inaplicación de aquel acto o con su invalidez (Bustamante 2001: 205).

En segundo lugar, está el «debido proceso procesal», conformado por un conjunto de derechos esenciales que impiden que la libertad y los derechos de los individuos sucumban ante la ausencia o insuficiencia de un proceso o procedimiento, o se vean afectados por cualquier sujeto de derecho - incluyendo el Estado- que 
pretenda hacer uso abusivo de estos (Bustamante 2001: 207-208). Entre dichos derechos figura uno, el cual consiste en «[...] que se asegure la eficacia o ejecución de las decisiones que se emitan o que hayan sido emitidas, y a que se dicten las medidas necesarias para que estas se cumplan, por ejemplo, a través de medidas cautelares [...]» (Bustamante 2001: 215).

La previsión contenida en el inciso 3 del artículo 139 de la Constitución estaría referida solo al debido proceso procesal, conforme a la interpretación realizada por el Tribunal Constitucional al sentenciar el Expediente n. ${ }^{\circ}$ 2940-2002-HC/TC². Similar orientación asumió dicho Tribunal al sentenciar posteriormente el Expediente n. ${ }^{\circ}$ 0351-2004-AA/TC ${ }^{3}$. Lo anterior no frustra los avances de la doctrina sobre el reconocimiento de la existencia de una faceta sustancial del debido proceso.

\section{EL DEBIDO PROCESO Y EL PROCEDIMIENTO ADMINISTRATIVO PERUANO}

Hasta el año 1967, en Perú, dicha disciplina se expresaba positivamente a través de diversos reglamentos. Existían reglamentos para la minería, para la agricultura, para las aduanas, para los tributos, entre otros dictados por los ministerios; las municipalidades expedían sus propios reglamentos, así como las Fuerzas Armadas. El derecho administrativo era así uno de tipo eminentemente procedimentalista, pues los reglamentos, casi en su totalidad, se dedicaban solo a regular los procedimientos que se debían seguir ante los respectivos organismos públicos.

2 Sentencia del Tribunal Constitucional del 30 de agosto de 2003, en el proceso de habeas corpus seguido por Ramón Campos Esparza contra la Sala de Apelaciones para Procesos Sumarios con Reos Libres de la Corte Superior de Justicia de Lima.

3 Sentencia del Tribunal Constitucional de fecha 12 de mayo de 2004, en el proceso de amparo seguido por Jaime Chava Quispe contra la Primera Sala Civil de la Corte Superior de Justicia de Lima. 
El 11 de noviembre de 1967 fue expedido el Decreto Supremo n. ${ }^{\circ}$ 006-SC, que aprobaba el Reglamento de Normas Generales de Procedimientos Administrativos (en adelante, RNGPA). Con 117 artículos, el nombre y rango de dicho cuerpo normativo ilustra la situación anterior y explica lo que se buscó con su emisión. Si bien no se abandonó aún el rango reglamentario, se unificaron los criterios centrales de los reglamentos existentes en uno solo para todos los procedimientos administrativos existentes. El nuevo reglamento compartió vigencia con muchos de los reglamentos especiales referidos.

El salto hacia la legalidad tuvo lugar el 30 de diciembre de 1992, con la publicación del Decreto Ley n. ${ }^{\circ}$ 26111. Mediante dicho dispositivo, de rango legal, se introdujeron modificaciones al RNGPA, se cambió su denominación por la de Ley de Normas Generales de Procedimientos Administrativos (en adelante, LNGPA) y se ordenó en su artículo 9 que el Poder Ejecutivo aprobara el Texto Único Ordenado de dicha ley. Por primera vez, el procedimiento administrativo alcanzaba el rango de ley.

En ese sentido, el 28 de enero de 1994, el Ministerio de Justicia expidió el Decreto Supremo n. ${ }^{\circ}$ 02-94-JUS, que aprobó el Texto Único Ordenado de la Ley de Normas Generales de Procedimientos Administrativos (en adelante, TUO LNGPA). Como se comprenderá, los cambios descritos movilizaron a teóricos, justificaron escritos y publicaciones, y en general, interés por el derecho administrativo. La disciplina había cambiado. Sin embargo, el nuevo cuerpo normativo poseía un marcado sentido procedimentalista: teníamos un procedimiento administrativo con rango de ley. Pese a ser precedido por la Constitución del año 1993, el TUO LNGPA no asimilaba a la Administración pública como un sujeto obligado ante esta. Si bien se regulaban algunas garantías a favor del sujeto administrado, faltaba lo más importante. 
Los trabajos del Tribunal Constitucional instituido por la Constitución Política de 1993, el alineamiento de la Corte Suprema de la República a los valores y garantías constitucionales, el renovado interés por el derecho administrativo, no se manifestarían sino hasta los años 2000 y 2001. Cambios políticos en el país provocaron el despertar de todas estas variables y la necesidad de establecer una normativa administrativa que garantice los derechos constitucionales de los sujetos administrados ante la Administración pública.

Ello tuvo un punto final el 11 de abril y el 11 de octubre de 2001, días en los que se publicó y entró en vigor la Ley n. ${ }^{\circ} 27444$, denominada Ley del Procedimiento Administrativo General (en adelante, LPAG) ${ }^{4}$, en un inicio con 243 artículos. La característica central de dicha ley fue su fuerte sentido principista y garantista. Fue así que, al estilo de los códigos sustanciales o procesales peruanos, el legislador innovó introduciendo un Título Preliminar con los conceptos transversales de toda la ley, y con un listado de 16 «principios del procedimiento administrativo». Entre estos -el segundo del elenco-, hizo su aparición el llamado «principio del debido procedimiento administrativo» como expresión del debido proceso constitucional en sede administrativa, con especiales características.

Luego de modificaciones puntuales, una primera reforma a la LPAG estuvo a cargo del Decreto Legislativo n. ${ }^{\circ} 1029$, publicado el 24 de junio de 2008, dicha reforma no se involucró con la regulación de dicho principio. Pero la LPAG sufrió una segunda reforma, más importante, el 21 de diciembre de 2016, día en que apareció publicado en el Diario Oficial El Peruano el Decreto Legislativo n. ${ }^{0}$ 1272, modificando 62 de sus artículos. Entre los temas que sufrieron una variación figuraba el principio del debido procedimiento administrativo. El instrumento modificador ordenó

4 Su Cuarta Disposición Complementaria y Final dispuso una vacatio legis de seis meses. 
en su Sexta Disposición Complementaria y Transitoria la próxima aprobación de un Texto Único Ordenado. Esto se ha cumplido mediante el Decreto Supremo n. ${ }^{\circ}$ 006-2017-JUS, publicado el 20 de marzo de 2017 (en adelante TUO LPAG), que rige en la actualidad y sobre el cual volveremos luego.

\section{EL DEBIDO PROCEDIMIENTO ADMINISTRATIVO5}

¿Qué es el procedimiento administrativo para la doctrina? Analizando las características del derecho administrativo, apreciamos que está hecho: «de un equilibrio (por supuesto, difícil, pero posible) entre privilegios y garantías. En último término, todos los problemas jurídico-administrativos consisten $-\mathrm{y}$ esto conviene tenerlo bien presente- en buscar ese equilibrio, asegurarlo cuando se ha encontrado y reconstruirlo cuando se ha perdido» (García de Enterría y Fernández 2006: 53).

El procedimiento administrativo, como importante expresión del principio de legalidad en el derecho administrativo, y a su vez la mayor garantía que posee todo sujeto ante la administración, es el espacio que sirve para el desenvolvimiento de los privilegios de la administración y para el ejercicio de las garantías de los administrados frente a estas. Podemos conceptualizarlo como: «el instrumento jurídico por el que se viabiliza el actuar de la relación administrado-Administración», que constituye «la herramienta más idónea como reaseguro contra los desbordes del obrar de la Administración», ello en la medida que

el procedimiento administrativo regla el ejercicio de la prerrogativa pública y de los derechos subjetivos y libertades públicas. [...] es,

5 En este acápite, seguimos varias de las ideas vertidas en nuestro artículo «¿Qué es el debido procedimiento administrativo?» (Jiménez 2007: 166-170); ideas precisadas y actualizadas, sin perjuicio de la información producida con posterioridad a dicha publicación, considerada y valorada en esta ocasión. 
en suma, un instrumento de gobierno y de control. Cumple una doble misión republicana: el ejercicio del poder por los carriles de la seguridad y la legalidad, y la defensa de los derechos por las vías procesales recursivas y reclamativas (Dromi 1998: 889-890).

Dentro del marco garantista recién descrito, constituido por el procedimiento administrativo, también se inscribe el debido proceso constitucional, el cual por ese hecho es denominado «debido procedimiento», y que adoptó en sede administrativa particulares características. Según un tempranero comentario al texto original de la LPAG, dicho principio: «constituye una garantía general de los ciudadanos que ha sido introducida al Derecho administrativo primero por la jurisprudencia, derivándola del derecho natural y de los tratados internacionales de derechos humanos» (Morón 2001: 29).

Al igual que el debido proceso constitucional, el debido procedimiento es un conjunto de garantías para el administrado ante la Administración a través del procedimiento administrativo. Un estudio comparativo de diversas legislaciones latinoamericanas, efectuado justo durante los primeros años de vigencia de la LPAG peruana, nos brinda una relación de las principales garantías del debido procedimiento:

1. El principio del contradictorio.

2. El derecho a la defensa.

3. El principio de la gratuidad.

4. El principio de la motivación de los actos administrativos.

5. El principio de la confianza legítima.

6. El tema de la garantía de la tutela judicial efectiva y su relación con el principio del agotamiento de la vía administrativa (Brewer-Carías 2003: 262). 
¿Y que ha revelado la jurisprudencia sobre nuestro tema? Partiendo de la idea de que la consagración constitucional del debido proceso permite su vigencia más allá de los límites de la función jurisdiccional, desde hace varios años, el Tribunal Constitucional ha buscado esos otros alcances en diversos pronunciamientos. Podemos hallar una aproximación al tema en una sentencia dictada por el Tribunal Constitucional el 2 de julio de 1998, sobre la transgresión de lo que denominó «debido proceso administrativo»:

4. [...] el debido proceso administrativo, supone en toda circunstancia el respeto por parte de la administración pública de todos aquellos principios y derechos normalmente invocados en el ámbito de la jurisdicción común o especializada y a los que se refiere el artículo 139 de la Constitución del Estado (verbigracia: jurisdicción predeterminada por la ley, derecho de defensa, pluralidad de instancia, cosa juzgada, etc. $)^{6}$.

Las conclusiones de la citada búsqueda las encontramos en la sentencia dictada el 29 de agosto de 2006 en el Expediente n. ${ }^{\circ} 3075$ 2006-PA/TC:

4. [...] el debido proceso es un derecho fundamental de naturaleza procesal con alcances genéricos, tanto en lo que respecta a los ámbitos sobre los que se aplica como en lo que atañe a las dimensiones sobre las que se extiende. Con relación a lo primero, queda claro que dicho atributo desborda la órbita estrictamente judicial para involucrarse o extenderse en otros campos como el administrativo, el corporativo particular, el parlamentario, el castrense, entre muchos otros, dando lugar a que [...] pueda hablarse de un debido proceso jurisdiccional, de un debido proceso administrativo, de un debido proceso corporativo particular, de un debido proceso

6 Sentencia del Tribunal Constitucional dictada el 2 de julio de 1998 en el Expediente n. ${ }^{\circ}$ 026-97-AA/TC, seguido por Empresa de Transportes Andrés Avelino Cáceres contra la Municipalidad Provincial de Huánuco, sobre acción de amparo. 
parlamentario, etc. Por lo que respecta a lo segundo [...] las dimensiones del debido proceso no solo responden a ingredientes formales o procedimentales, sino que se manifiestan en elementos de connotación sustantiva o material [...] su evaluación no solo repara en las reglas esenciales con las que se tramita un proceso (juez natural, procedimiento preestablecido, derecho de defensa, motivación resolutoria, instancia plural, cosa juzgada, etc.), sino que también, y con mayor rigor, se orienta a la preservación de los estándares o criterios de justicia sustentables de toda decisión (juicio de razonabilidad, juicio de proporcionalidad, interdicción de la arbitrariedad, etc.). Así las cosas, el debido proceso es un derecho de estructura compleja, cuyos alcances corresponde precisar a la luz de los ámbitos o dimensiones en cada caso comprometidas $[. . .]^{7}$.

Entonces, entre los ámbitos del debido proceso, aquel referido al derecho administrativo («debido proceso administrativo»), al igual que en los otros ámbitos, puede alcanzar dimensiones tanto formales como sustanciales. Para el Tribunal Constitucional peruano, las garantías del debido proceso jurisdiccional encontraban plena aplicación en sede administrativa, configurando el «debido proceso administrativo» como un conjunto de garantías jurisdiccionales, también exigibles ante la Administración pública en un segundo momento.

El 26 de agosto de 2003 el Tribunal Constitucional declaró fundada una demanda de inconstitucionalidad contra la Ordenanza n. ${ }^{\circ} 290$ de la Municipalidad Metropolitana de Lima, referida a la inclusión del recurso de revisión en un procedimiento ante la municipalidad. El Tribunal, en su tercer fundamento, precisó que:

7 Sentencia del Tribunal Constitucional expedida el 26 de agosto de 2006, en el Expediente n. ${ }^{\circ}$ 03075-2006-PA/TC, seguido por la Escuela Internacional de Gerencia High School of Management-EIGER contra Indecopi, y otra sobre proceso de amparo. 
[...] En efecto, el derecho a la pluralidad de instancias no es un contenido esencial del derecho al «debido proceso administrativo» - pues no toda resolución es susceptible de ser impugnada en dicha sede-; pero sí lo es del derecho al debido proceso «judicial», pues la garantía que ofrece el Estado constitucional de derecho es que las reclamaciones de los particulares contra los actos expedidos por los órganos públicos, sean resueltas por un juezindependiente, imparcial y competente, sede esta en la que, además, se debe posibilitar que lo resuelto en un primer momento pueda ser ulteriormente revisado, cuando menos, por un órgano judicial superior ${ }^{8}$.

\begin{abstract}
El Tribunal identificaba al aún llamado debido proceso administrativo (pese a estar ya vigente la Ley n. ${ }^{\circ}$ 27444) como un derecho distinto al debido proceso judicial, pero le reconocía el mismo nivel. Se advierte un avance interpretativo. Con fecha 26 de agosto de 2004, el Tribunal Constitucional peruano mostró la institución que estudiamos de una tercera manera en su sexto fundamento:
\end{abstract}

Todo ejercicio de la potestad administrativa debe observar la Ley del Procedimiento Administrativo General, ley marco que regula la actuación administrativa. Al respecto, el artículo IV del Título Preliminar, consagra, entre otros, el derecho al debido procedimiento, que garantiza que los administrados gocen de derechos tales como el de exponer sus argumentos, de ofrecer y producir pruebas y obtener una decisión motivada y fundamentada en el derecho'.

8 Sentencia del Tribunal Constitucional del 26 de agosto de 2003, en el Expediente n. ${ }^{\circ}$ 010-2001-AI/TC, seguido por el Defensor del Pueblo contra la Municipalidad Metropolitana de Lima, sobre proceso de inconstitucionalidad.

9 Sentencia del Tribunal Constitucional del 29 de agosto de 2004, en el Expediente n. $1628-2003-A A / T C$, seguido por la Fundación Ignacia R. vda. de Canevaro contra la Superintendencia de Bienes Nacionales, sobre acción de amparo. 
Según esta sentencia, el ahora sí llamado debido procedimiento (administrativo) es la garantía que tienen los administrados del respeto al procedimiento administrativo y garantías previstos en la LPAG.

El Tribunal Constitucional avanzó más al sentenciar con fecha 17 de febrero de 2005 el Expediente n. ${ }^{\circ}$ 4289-2004-AA/TC, al resolver sobre una infracción al derecho a un debido proceso en sede administrativa:

2. El Tribunal Constitucional estima oportuno recordar, conforme lo ha manifestado en reiterada y uniforme jurisprudencia, que el debido proceso, como principio constitucional, está concebido como el cumplimiento de todas la garantías y normas de orden públicos que deben aplicarse a todos los casos y procedimientos, incluidos los administrativos, a fin de que las personas estén en condiciones de defender adecuadamente sus derechos ante cualquier acto del Estado que pueda afectarlos. Vale decir que cualquier actuación u omisión de los órganos estatales dentro de un proceso, sea este administrativo - como en el caso de autos- o jurisdiccional, debe respetar el debido proceso legal ${ }^{10}$.

Si bien el debido proceso está constitucionalizado como un conjunto de garantías en sede judicial, se trata antes de ello de un derecho constitucional, que debe ser respetado tanto por el Poder Judicial como por la Administración pública. Esta vez, el Tribunal Constitucional colocó a ambas instituciones en pie de igualdad (tercer fundamento): «El derecho al debido proceso, y los derechos que contiene son invocables, $\mathrm{y}$, por tanto, están garantizados, no solo en el seno de un proceso judicial, sino también en el ámbito del procedimiento administrativo» (Tribunal Constitucional 2005a: 2).

10 Sentencia del Tribunal Constitucional del 17 de febrero de 2005, en el Expediente n. ${ }^{\circ}$ 4289-2004-AA/TC, seguido por Blethyn Oliver Pinto contra la Comandancia General del Ejército, sobre acción de amparo. 
El derecho al debido proceso resulta así aplicable por igual ante ambos estamentos. Sin embargo, el cuarto acápite de la sentencia indica que:

El fundamento principal por el que se habla de un debido proceso administrativo, encuentra sustento en el hecho de que tanto la administración como la jurisdicción están indiscutiblemente vinculadas a la Carta Magna, de modo que si la administración resuelve sobre asuntos de interés del administrado, y lo hace mediante procedimientos internos, no existe razón alguna para desconocer la categorías invocables ante el órgano jurisdiccional (Tribunal Constitucional 2005a: 2-3).

El Tribunal precisa que tanto la jurisdicción como la administración se encuentran supeditadas a la Constitución. Por ello, las garantías previstas para los procesos judiciales en los cuales se resuelve sobre derechos y obligaciones de las personas, resultan perfectamente aplicables a los procedimientos administrativos, en los que se resuelve sobre los derechos e intereses de los sujetos administrados. El Tribunal, sin embargo, retrocedió a la expresión «debido proceso administrativo», pese a que había sido superada por la LPAG, vigente ya cuatro años.

Y finalmente, ¿cómo está regulado el principio del debido procedimiento en la Ley del Procedimiento Administrativo General peruana? Son dos las regulaciones que ha recibido dicho principio en la mencionada ley peruana: una inicial, vigente desde octubre del año 2001 hasta diciembre de 2016, y otra planteada con la reforma de fines de dicho año, hoy recogida en su Texto Único Ordenado. ¿Cuál fue el cambio entre una y otra? El artículo IV de la LPAG en el texto original de su numeral 1.2 lo establecía de la siguiente manera: 
Artículo IV.- Principios del procedimiento administrativo. [...]

Principio del debido procedimiento.- Los administrados gozan de todos los derechos y garantías inherentes al debido procedimiento administrativo, que comprende el derecho a exponer sus argumentos, a ofrecer y producir pruebas, a obtener una decisión motivada y fundada en derecho. La institución del debido procedimiento administrativo se rige por los principios del Derecho administrativo. La regulación propia del Derecho Procesal Civil es aplicable solo en cuanto sea compatible con el régimen administrativo $[\ldots]$

La nueva redacción del principio, luego de la reforma del año 2016 es como sigue:

Artículo IV.- Principios del procedimiento administrativo. [...]

Principio del debido procedimiento.- Los administrados gozan de todos los derechos y garantías implícitos al debido procedimiento administrativo. Tales derechos y garantías comprenden, de modo enunciativo mas no limitativo, los derechos a ser notificados; a acceder al expediente; a refutar los cargos imputados; a exponer argumentos y a presentar alegatos complementarios; a ofrecer y a producir pruebas; a solicitar el uso de la palabra, cuando corresponda; a obtener una decisión motivada, fundada en derecho, emitida por autoridad competente, y en un plazo razonable; y a impugnar las decisiones que los afecten [...].

\section{ACTUALIDAD Y FUTURO: POSIBILIDADES COMPARATIVAS}

Nuestro estudio no se detiene en la triple visión de la doctrina, jurisprudencia y legislación. Cabe preguntarse ¿qué significa tal transformación?, ¿cuál es su contenido y cuáles son sus alcances?, ¿hacia dónde camina el derecho peruano en esta materia? Finalmente, ¿tiene esta experiencia alcances comparativos? 


\subsection{Expresión de una verdadera eficacia vertical $y$ horizontal del derecho al debido proceso en el derecho administrativo}

Entre las características de los derechos fundamentales, figuran su mayor valor respecto a los demás derechos, su doble dimensión objetiva y subjetiva, su fuerza expansiva, y su eficacia horizontal y vertical, entre otros. Nuestro tema nos permite referirnos a esta última. En su formulación inicial, los derechos fundamentales surgieron como inmunidades frente al poder público del Estado; $y$, en ese sentido, el constitucionalismo fue una técnica de control y restricción de dicho poder público y de cualquier otro privado. Actualmente, se reconoce que los derechos fundamentales tienen una eficacia vertical, que se expresa ante el poder estatal (figurativamente de arriba hacia abajo) y una eficacia horizontal, que se muestra entre pares, lo que equivale a que tales derechos también rigen las relaciones entre particulares (Sosa 2011: 127-128).

Los derechos fundamentales, desde su origen, fueron concebidos como derechos frente al Estado; situación que tuvo que experimentar una importante mutación cuando dichos derechos, además de su carácter subjetivo, fueron además concebidos como componentes estructurales de los ordenamientos constitucionales. Esto último permitió que los derechos fundamentales sean vistos como mandatos de actuación y deberes de protección especial de los poderes públicos, y también como derechos capaces de informar e irradiarse en las relaciones entre particulares, actuando como límites a la autonomía privada (Carpio 2004: 73). Pues bien, el derecho al debido proceso ha ganado efectos verticales y horizontales sobre los sujetos que interactúan dentro del derecho administrativo peruano, y la clave es el derecho al debido procedimiento administrativo. Ello a partir del texto de la propia LPAG y de los desarrollos efectuados por la jurisprudencia constitucional. 
En cuanto al marco normativo, la LPAG y luego el TUO LPAG consideran en el artículo I de su Título Preliminar como «entidades de la Administración pública» al Poder Ejecutivo incluyendo sus Ministerios, a los Poderes Legislativo y Judicial (en sus secciones pertinentes), a los gobiernos regionales y locales, entre otros sujetos integrantes del Estado; pero también incluye como tales a las personas jurídicas privadas que presten algún servicio público en virtud de una concesión, delegación o autorización del Estado. Luego, al recoger el derecho al debido procedimiento administrativo, lo presentan como un conjunto de garantías de origen jurisdiccional, aplicables a los procedimientos administrativos en cuanto son elementos integrantes del derecho fundamental al debido proceso.

Dicho marco normativo describe la existencia de potestades administrativas que ejercen todos esos organismos administrativos respecto de los sujetos administrados cuya actividad recae dentro de sus respectivas competencias (eficacia vertical); pero también contempla la presencia de relaciones entre dichos sujetos privados con otros similares que ejercen funciones administrativas por motivo de concesión, delegación o autorización del Estado (eficacia horizontal).

Respecto a la jurisprudencia, cabe referirnos a lo mencionado al citar el cuarto fundamento de la sentencia expedida por el Tribunal Constitucional en el proceso de amparo seguido por la Escuela Internacional de Gerencia High School of Management (EIGER) contra el Instituto de Defensa de la Competencia y de Protección de la Propiedad Intelectual (Indecopi) y otra, comentada en el acápite anterior. En tal ocasión, dicho Tribunal consideró la existencia de ámbitos del debido proceso en sede administrativa, como son el administrativo, el corporativo particular, el parlamentario, el castrense, entre otros, dando lugar a que, en cada caso, pueda hablarse de un debido proceso administrativo, de un debido proceso corporativo particular, de un debido proceso parlamentario, etc.; 
espacios que engloban diversas manifestaciones del poder del Estado (eficacia vertical) como relaciones entre privados en torno a un debido procedimiento (eficacia horizontal). Tales ideas han sido recogidas en sentencias posteriores ${ }^{11}$.

\subsection{Manifestación del derecho al debido proceso en posiciones jurídicas concretas}

El debido proceso, como derecho fundamental y constitucional, luego de ser positivizado, se concretiza en puntuales relaciones de derecho administrativo, bajo la forma de debido procedimiento administrativo. En la sentencia dictada por el Tribunal Constitucional el 8 de julio de 2005 en el Expediente n. ${ }^{\circ}$ 1417-2005-AA/ TC (conocido como el caso Anicama Hernández), el fundamento jurídico n. ${ }^{\circ}$ 24, al desarrollar la estructura de los derechos fundamentales, enuncia lo siguiente:

Las disposiciones de derecho fundamental son los enunciados lingüísticos de la Constitución que reconocen los derechos fundamentales de la persona. Las normas de derecho fundamental son los sentidos interpretativos atribuibles a esas disposiciones. Mientras que las posiciones de derecho fundamental, son las exigencias concretas que al amparo de un determinado sentido interpretativo válidamente atribuible a una disposición de derecho fundamental, se buscan hacer valer frente a una determinada persona o entidad ${ }^{12}$.

Lo que permite el debido procedimiento administrativo es que el debido proceso se concretice en específicas posiciones o puntuales exigencias concretas que realizan los sujetos administrados en los

11 Como ha ocurrido, por ejemplo, en el fundamento n. ${ }^{\circ} 3$ de la sentencia recaída en el Expediente n. ${ }^{\circ}$ 00156-2012-PHC/TC.

12 Sentencia del Tribunal Constitucional expedida el 8 de julio de 2005 en el Expediente n. ${ }^{o}$ 1417-2005-AA/TC, seguido por Manuel Anicama Hernández contra la Oficina de Normalización Previsional, sobre acción de amparo. 
distintos procedimientos administrativos. Posibilita que estos sujetos exijan en sus particulares casos ante la Administración, el respeto a su derecho de acceder al expediente, el ejercicio de su derecho a refutar los cargos imputados, la práctica de su derecho a exponer sus argumentos, etc. En todos los casos, los sujetos administrados tendrán un respaldo constitucional: su derecho al debido proceso.

\subsection{Extensión del debido proceso al derecho administrativo, adaptándose a los caracteres esenciales de dicha disciplina jurídica}

El derecho a un debido procedimiento administrativo recogido hoy en el TUO LPAG, responde, en principio, al desarrollo doctrinario del derecho a un debido proceso judicial, esencial en el ejercicio de la función jurisdiccional, que es consagrado como un derecho constitucional. Debido a ello, este derecho extiende sus alcances más allá de dicha función, hacia ámbitos en los cuales el Estado también declara derechos e impone obligaciones, uno de los cuales se presenta en el ejercicio de la función administrativa, encargado a la Administración pública.

Sin embargo, relacionar la noción de debido proceso con el desempeño habitual de la Administración nos obliga a repensar los caracteres originales de dicha categoría. No nos encontramos ya dentro del desenvolvimiento de la función jurisdiccional, sino dentro del campo correspondiente a otra función estatal: la función administrativa. Por ello $-\mathrm{y}$ porque el debido proceso está catalogado como un derecho constitucional- su aplicación en sede administrativa asume los matices de aquella otra función. Así se explica la independencia y propia identidad del debido procedimiento administrativo, lo cual tiene un doble significado. Por un lado, es la aplicación del debido proceso constitucional a la relación existente entre la Administración pública y los sujetos administrados; o, dicho de otro modo, el respeto por parte de la 
primera a los derechos y garantías previstos a favor de tales sujetos, sin carácter literal ni número cerrado ${ }^{13}$.

Por otro lado, importa un cambio de paradigma en la visión del debido proceso constitucional. Este fue pensado como un derecho aplicable a una relación jurídica procesal en la cual el órgano estatal interviniente cumple sus funciones como sujeto distinto a las partes involucradas en cada proceso. En cambio, en sede administrativa, encontramos relaciones jurídicas mayormente encabezadas por un organismo del Estado que ejerce potestades respecto de los sujetos administrados (concretamente, su derecho de autotutela, en sus formas de cognición, resolutiva y ejecutiva), ámbito en que su eficacia será vertical; y minoritariamente relaciones jurídicas entre privados, en los casos en que uno de estos ejerce un servicio público por concesión, delegación o autorización, segmento en el cual su eficacia será horizontal.

\subsection{El debido procedimiento administrativo como derecho de desarrollo jurisprudencial, con un rol orientador de la doctrina y un reconocimiento legal abierto}

Sin perjuicio de su planteamiento doctrinario y regulación normativa, el debido procedimiento administrativo es un concepto que, en Perú, ha sido desarrollado en vía jurisprudencial, lo que ha ocurrido con varios otros derechos.

Legislativamente hablando, ya se indicó con anterioridad ${ }^{14}$ que el debido procedimiento administrativo apareció en el texto inicial de la LPAG y se mantuvo hasta la reforma del año 2016, cuando el Decreto Legislativo n. ${ }^{\circ} 1272$ modificó el anterior ampliando sus

13 Sobre esto último, el «debido procedimiento administrativo», tal como aparece regulado en el TUO LPAG, indica que los administrados gozan de los derechos y garantías «implícitos» al debido procedimiento administrativo, cita luego un listado de estos derechos y garantías en expreso «modo enunciativo».

14 Ver acápite 6.3 anterior. 
alcances. La doctrina, por su parte, ha acompañado la evolución jurisprudencial y legislativa del instituto comentado. Sin perjuicio de la doctrina citada hasta aquí, un comentario un tanto reciente aporta en el sentido de que los alcances del derecho al debido procedimiento administrativo regulados en Perú, tendrían un antecedente en el literal $f$ del artículo 1 del Decreto Ley n. ${ }^{\circ}$ 19.549, Ley de Procedimiento Administrativo de Argentina (Huapaya 2016: 140).

$\mathrm{Al}$ respecto, nosotros consideramos que si bien los tres numerales del literal $\mathrm{f}$ del dispositivo argentino citado pueden asimilarse a los tres derechos considerados en el texto original de la LPAG peruana, el legislador argentino actuó movido por una mayor necesidad de especificaciones, que diferencian el texto de su norma de aquel peruano. Sin perjuicio de ello, la modificación del derecho al debido procedimiento administrativo peruano, acaecido en la reforma del año 2016, implicó la asunción de otro paradigma: el de la consideración de un conjunto de derechos y garantías de manera enunciativa y abierta, con vocación de expansión, lo que recoge una de las características del derecho al debido proceso (en tanto derecho fundamental) que le sirve de premisa. Nos referimos aquí a una opción normativa estrictamente peruana en la regulación del debido procedimiento administrativo.

\subsection{Configuración del procedimiento administrativo como un deber de la Administración pública, de planteamiento genérico pero de exigencia particular ${ }^{15}$}

La LPAG en su texto original enumeraba algunos derechos y en su texto actual considera más de estos. Tal tendencia puede ser vista

15 En este acápite, seguimos parte de las ideas vertidas en nuestro artículo «El procedimiento administrativo como derecho y como deber» (Jiménez 2008: 337-345); ideas aquí precisadas y actualizadas, sin perjuicio de la información producida con posterioridad a dicha publicación, considerada y valorada en esta ocasión. 
como la forma en que el debido proceso constitucional aporta, acerca y adapta su carácter garantista al procedimiento administrativo, al punto de convertirlo tanto en un derecho para los administrados como en un deber para la administración. Al respecto, el Tribunal Constitucional, con fecha 17 de junio de 2008, dictó sentencia en el Expediente n. ${ }^{\circ}$ 04225-2006-PA/TC. Citando la regulación del derecho a un debido procedimiento, indica el Tribunal que este: «determina que los administrados gozan de todos los derechos y garantías, como el derecho a exponer sus argumentos, a ofrecer y producir prueba y a obtener una decisión motivada y fundamentada en derecho» ${ }^{16}$.

Entonces, el Tribunal Constitucional identifica tres momentos en el tratamiento del derecho a un debido procedimiento. El primero se relaciona con el derecho de petición, el segundo con el derecho de defensa dentro del procedimiento, y el tercero con el deber de la administración de resolver solicitudes y controversias. Seguidamente, el Tribunal se concentra en la primera de tales etapas y señala que esta: «[...] se refiere al debido proceso como derecho al procedimiento administrativo y supone que todos los administrados tienen el derecho a la existencia de un procedimiento administrativo previo a la producción de las decisiones administrativas que les conciernan $[\ldots] »(2008: 3)$.

De acuerdo con ello, el debido proceso constitucional encuentra tres manifestaciones en el ámbito administrativo. La primera de ellas es el derecho a un procedimiento administrativo, es decir, el derecho de los sujetos administrados a que sus peticiones sean atendidas por las entidades mediante un procedimiento. Dicho de otra manera, el debido procedimiento es el derecho de tales sujetos

16 Sentencia del Tribunal Constitucional dictada el 17 de julio de 2008, en el Expediente n. ${ }^{\circ}$ 4225-2006-PA/TC, seguido por Marcelino Bances Pizarro contra la Zona Registral n. ${ }^{\circ}$ V -Sede Trujillo- (antes Oficina Registral de La Libertad), sobre proceso de amparo. 
a que sus peticiones sean atendidas garantizando el equilibrio entre los derechos e intereses de los requirentes y las potestades públicas ejercidas por la autoridad.

Continuando, el Tribunal indica que «[...] la Administración tiene el deber de producir sus decisiones mediante el cumplimiento de las reglas que conforma el procedimiento [...]». Esto es así si vemos que uno de los principales fundamentos de la existencia del procedimiento es el constituirse en la herramienta que permita interdictar cualquier ejercicio arbitrario del poder público, finalidad paralela al equilibrio entre derechos, intereses y potestades antes señalados.

Un segundo fundamento de dicho deber de la Administración lo encontramos en el artículo III del Título Preliminar del TUO LPAG. Dicha norma señala que la función administrativa del Estado tiene por finalidad servir a la protección del interés general, garantizando los derechos e intereses de los administrados, pero agrega que tanto la finalidad, al igual que las garantías, se cumple con sujeción al ordenamiento constitucional y jurídico en general, dentro del cual se sitúa obviamente el TUO LPAG y cualquier otra norma reguladora de algún procedimiento especial.

Así, el procedimiento administrativo es un deber para la Administración también debido al contenido esencial del derecho de petición. Este derecho debe ser exigido por los sujetos administrados a la Administración en cada procedimiento en concreto; del mismo modo, compromete a esta a cumplir el mencionado derecho de diversas formas, las cuales ordenadas temporal y funcionalmente describen en su conjunto al procedimiento mismo.

\section{IDEAS FINALES}

Son tres las principales fuentes del derecho: la doctrina, la legislación y la jurisprudencia. Estas generan al derecho, pero también lo retroalimentan y lo recrean a cada momento. De la permanente 
atención a sus cambios por parte del estudioso, dependerá su capacidad de dar respuestas oportunas y precisas a los fenómenos y problemas que se presentan en la sociedad.

Nuestro estudio es uno forjado a partir de la interacción de las tres fuentes indicadas, concretamente en su interacción a través de un camino: aquel descrito por el debido proceso como derecho humano, hacia el interior del derecho administrativo peruano; recorrido a cuyo final se ha transformado en el debido procedimiento administrativo. Dicho recorrido, sin embargo, ha servido al debido proceso para desplegar nuevos elementos garantistas, propios de la disciplina mencionada, con alcances que van más allá de la experiencia nacional descrita.

Hemos visto cómo el debido proceso alcanza una verdadera eficacia vertical y horizontal en el derecho administrativo. Hemos descrito la forma en que el debido proceso logra su concreción en determinadas posiciones jurídicas de derecho administrativo. Hemos comentado que tal extensión del debido proceso al derecho administrativo representó su adaptación a los caracteres esenciales de dicha disciplina jurídica. Hemos presentado también al debido procedimiento administrativo como un derecho de desarrollo jurisprudencial, orientado por la doctrina y con un reconocimiento legal abierto. Finalmente, hemos presenciado que el debido procedimiento administrativo ha permitido configurar al procedimiento administrativo como un deber de la Administración pública, de planteamiento genérico, pero de exigencia en cada concreto procedimiento.

Tales facetas del derecho al debido proceso son de interés para el estudioso constitucionalista, administrativo o comparado. Lo esencial ha sido expresado, pero la evolución del tema continúa: sigamos atentos su decurso. 


\section{REFERENCIAS BIBLIOGRÁFICAS}

BARber, Sortirios A. (1986). Sobre el significado de la Constitución de los EE. UU. Buenos Aires: Abeledo-Perrot.

Bastos Pinto, Manuel et al. (2012). Diccionario de derecho constitucional contemporáneo. Lima: Gaceta Jurídica.

Brewer-Carías, Allan R. (2003). Principios del procedimiento administrativo en América Latina. Bogotá: Legis.

Bustamante Alarcón, Reynaldo (2001). Derechos fundamentales y proceso justo. Lima: ARA Editores.

Carpio Marcos, Edgar (2004). La interpretación de los derechos fundamentales. Lima: Palestra Editores.

Dromi, Roberto (1998). Derecho administrativo. 7. a edición. Buenos Aires: Ciudad Argentina.

García de Enterría, Eduardo y Fernández, Tomás-Ramón (2006). Curso de derecho administrativo. Tomo II. 8. a edición. Madrid: Civitas.

GimenoSendra, Vicente; Torres del Moral, Antonio; Morenilla Allard, Pablo y Díaz Martínez, Manuel (2007). Los derechos fundamentales y su protección jurisdiccional. Madrid: Colex.

Huapaya Tapia, Ramón (2016). «Perspectivas actuales del procedimiento administrativo, en particular, el derecho a la tutela administrativa efectiva». Derecho administrativo: hacia un Estado más confiable. Libro de ponencias del VII Congreso Nacional de Derecho Administrativo. Lima: Thomson Reuters.

Jiménez Vivas, Javier (2007). «¿Qué es el debido procedimiento administrativo?». Revista Actualidad Jurídica, t. 167, 166-170. (2008). «El procedimiento administrativo como derecho y como deber». Revista Gaceta Constitucional, t. 10, 337-345. 
Morón Urbina, Juan (2001). Comentarios a la nueva ley del procedimiento administrativo general. Lima: Gaceta Jurídica.

Pisa University Press (2016). La Costituzione italiana. Pisa: Pisa University Press.

Sosa SAcio, Juan Manuel (2011). Guía teórico-práctica para utilizar los criterios interpretativos del Tribunal Constitucional. Lima: Gaceta Jurídica.

Tribunal Constitucional (1998). Expediente $n .{ }^{\circ}$ 026-97-AA/ TC. Huánuco: 2 de julio de 1998. Recuperado de https://www. tc.gob.pe/jurisprudencia/1998/00026-1997-AA.html (2003a). Expediente n. ${ }^{\circ}$ 2940-2002-HC/TC. Lima: 30 de enero de 2003. Recuperado de https://tc.gob.pe/jurisprudencia/2003/ 02940-2002-HC.pdf

(2003b). Expediente n. ${ }^{\circ}$ 010-2001-AI/TC. Lima: 26 de agosto de 2003. Recuperado de https://www.tc.gob.pe/ jurisprudencia/2003/00010-2001-AI.html

(2004a). Expediente n. ${ }^{\circ}$ 0351-2004-AA/TC. Lima: 12 de mayo de 2004. Recuperado de https://tc.gob.pe/jurisprudencia/ 2004/00351-2000-AA.pdf

(2004b). Expediente n. ${ }^{\circ}$ 1628-2003-AA/TC. Lima: 29 de agosto de 2004. Recuperado de http://tc.gob.pe/jurisprudencia/2004/ 01628-2003-AA.pdf (2005a). Expediente n. ${ }^{\circ}$ 4289-2004-AA/TC. Pisco: 17 de febrero de 2005. Recuperado de https://tc.gob.pe/jurisprudencia/2005 104289-2004-AA.pdf

(2005b). Expediente n. ${ }^{\circ}$ 1417-2005-AA/TC. Lima: 8 de julio de 2005. Recuperado de https://www.tc.gob.pe/jurisprudencia/ 2005/01417-2005-AA.html

(2006). Expediente n. ${ }^{\circ}$ 03075-2006-PA/TC. Arequipa: 29 de agosto de 2016. Recuperado de https://www.tc.gob.pe/ jurisprudencia/2006/03075-2006-AA.html 
(2008). Expediente n. ${ }^{\circ}$ 4225-2006-PA/TC. Lima: 17 de julio de 2008. Recuperado de https://tc.gob.pe/jurisprudencia/2008 /04225-2006-AA.pdf

United States Congress (1993). The Constitution of United States of America in various foreign languages. Washington D. C.: Law Library of Congress.

Ureña Carazo, Belén (2014). Derechos fundamentales procesales. Navarra: Arazandi. 